\title{
ENSAIO SOBRE A ECONOMIA FLUMINENSE: DA CRISE HISTÓRICO-ESTRUTURAL ALHEADA À CRISE MANIFESTA*
}

\author{
Jorge Luiz Alves Natal ${ }^{1}$ \\ Orcid: https://orcid.org/0000-0002-8802-9259
}

José Luis Vianna da Cruz ${ }^{2}$

Orcid: https://orcid.org/0000-0001-9869-2639

Recebido em: 11 fev. 2021

Publicado em: 28 abr. 2021

\begin{abstract}
RESUMO
O ensaio examina a denominada crise da economia fluminense, particularmente a da capital - Rio de Janeiro. A tese central defendida é que, em verdade, as crises da economia fluminense são manifestações intermitentes de uma profunda e longeva crise estrutural, e que remontam à passagem do século XIX ao século XX, com alguns interregnos de crescimento e mudanças até a denominada retomada dos anos 1990, e alguns soluços de crescimento na primeira década dos anos 2000 - que os autores chamam de milagrinho, tomando por empréstimo o termo cunhado por Laura Carvalho (2018). Apontando o alheamento em relação à crise estrutural e às abordagens que consideram o território ou região que abrange o interior fluminense, o ensaio enuncia aspectos metodológicos, teóricos e propositivos relativos não só aos diagnósticos como também - e sobretudo - aos encaminhamentos capazes de responder aos desafios colocados para que o estado, em sua inteireza (e integradamente), cresça de maneira sustentada no tempo.
\end{abstract}

PALAVRAS-CHAVE: Estado do Rio de Janeiro. Crise histórico-estrutural. Economia e desenvolvimento fluminense.

\section{ESSAY ON THE FLUMINENSE ECONOMY: FROM THE HISTORICAL-STRUCTURAL CRISIS LINKED TO THE MANIFEST CRISIS}

\begin{abstract}
The essay examines the so-called crisis of the Rio de Janeiro economy, particularly that of the capital - Rio de Janeiro. The main thesis is that, indeed, the economic crises in the North of Rio de Janeiro State are a manifestation of a deep and long-lasting structural crisis. They date back to the 19th to the 20th centuries, with some intervals of growth and

\footnotetext{
* Pesquisa financiada pela FAPERJ.

Doutor pelo Instituto de Economia da Unicamp-SP, professor universitário aposentado pelo Instituto de Pesquisa e Planejamento Urbano e Regional-IPPUR, da Universidade Federal do Rio de Janeiro-RJ e professor e coordenador do Módulo Política Econômica e (para o) Desenvolvimento do Curso de Especialização em Políticas Públicas e Gestão Governamental da Universidade Candido Mendes-RJ.

${ }^{2}$ Cientista Social, Mestrado e Doutorado em PUR (UFRJ), Pós-Doc em Desenvolvimento Territorial e Políticas Públicas (UFRRJ), professor aposentado da UFF, em exercício no Programa de Pós Graduação em Planejamento Regional e Gestão de Cidades (mestrado e doutorado), da UCAM Campos, onde desempenha a função de Coordenador de Pesquisa.
} 
transformation until the resumption of the 1990's, and some responses of growth in the first decade of the 2000's. The authors call them "small miracle" (In Portuguese, milagrinho), borrowing the term coined by Laura Carvalho (2018). By focusing on the alienation in the structural crisis and the approaches that take into account the territory or region that covers the interior of Rio de Janeiro State, the essay describes methodological, theoretical, and propositional aspects concerning not only the analyses but also - and above all - the directions that meet the challenges posed so that the whole state (and integrally) grows in a consistent way in time.

KEYWORDS: Rio de Janeiro state. Historical-structural crisis. Fluminense economy and development.

\section{APRESENTAÇÃO}

Entre os estudiosos da temática economia fluminense ${ }^{3}$, do passado e do presente, há pelo menos um consenso: nunca se conseguiu constituir uma efetiva e muito menos longeva massa crítica envolvida com a sua análise. Ou seja: essa temática não interessou expressiva e regularmente aos pesquisadores brasileiros, e nem mesmo aos localizados nos limites 'regionais' em questão ${ }^{4}$ Pior: ela sequer interessou para valer aos intelectuais sediados no espaço carioca (em sua maioria vinculados aos órgãos públicos neles existentes), independentemente de suas nomeações político-administrativas ao longo do tempo, mesmo sendo nele que eles sempre estiveram concentrados ${ }^{5}$.

Duas razões explicam esse comportamento: o fato de o ex-distrito federal ter sido capital imperial e depois republicana por cento e noventa e sete anos (1763-1960) plasmou na 'região', em especial na então capital do País, um olhar, e não apenas da academia, mais atento sobre as questões nacionais do que sobre as locais; e isso de par com uma visão equivocado-idealizada acerca da natureza da expansão econômica da renda e do emprego verificada a traços largos desde o último quartel do século XIX até o final dos anos 1970 - mais uma vez notadamente no domínio político-administrativo hoje definido como município do Rio de Janeiro, posto que o antigo estado do Rio nunca

\footnotetext{
${ }^{3}$ Por economia fluminense, entenda-se a economia da 'região' atualmente definida como estado do Rio de Janeiro. A esse respeito, vide a nota que segue.

${ }^{4}$ Que antes, no período histórico a ser aqui examinado (1870-2019), abrigou recortes distintos (pela ordem): estado do Rio de Janeiro e Distrito Federal; estado do Rio de Janeiro e Guanabara; e, finalmente, estado do Rio de Janeiro, dada a chamada fusão.

5 Porém, face à expansão universitária do passado relativamente recente e ao maior número de pesquisadores com formação pós-graduada (processo esse que vem acontecendo desde os anos 1970), há atualmente mais pesquisadores envolvidos nas diversas regiões do estado com o que se poderia denominar genericamente de estudos fluminenses - em regra, referidos aos espaços geográficos de seus endereços institucionais.
} 
apresentou performance a destacar na cena nacional (como se analisará...) ${ }^{6}$. Pode-se dizer assim que esses dois fatos históricos e seus respectivos olhares obscureceram o entendimento dos problemas estruturais tanto da economia carioca, em especial, quanto da fluminense como um todo.

É dizer: de um lado, os problemas mencionados foram alheados por conta da crença de que, ao sediar o Estado, ele 'era (até 1960) do Rio"7 e do suposto (falso) que bastava considerar o crescimento da renda e do emprego para analisar/entender a economia - no caso, a carioca, e, de outro, o igual alheamento do 'atraso' da (economia) situada do 'outro lado da baía', graças, pelo menos, aos fatores já apontados na nota cinco (ou seja, sua pouca importância econômica, institucional e reflexiva vis à vis à ex-capital do país). Nesses termos, no limite, daí emerge o seguinte fato: a negação da 'região' como um todo enquanto objeto de estudo nesse longo intervalo temporal.

Deixando de lado, no momento, a economia do antigo estado do Rio de Janeiro, não surpreende que, de um lado, as sugeridas fragilidades estruturais da economia carioca tenham sido ignoradas e, de outro, imbricadamente, numa espécie de corolário, com a crise econômica nacional dos anos 1960, e mais marcadamente com a dos 1980, que as análises tenham sido caracterizadas por um traço distintivo: o da sua vitimização face ao governo federal por conta da transferência da capital para Brasília e, adiante, pela fusão do antigo estado da Guanabara com o também antigo estado do Rio. Transferência da capital para Brasília, fusão do antigo estado do Rio com a também antiga Guanabara e abandono/responsabilização de terceiros (União/Governo Federal) combinaram-se ali à perfeição nessa narrativa! Daí a 'venda' da tese de que a crise longevo-estrutural teria começado com a referida transferência e, por causa, sido 'apenas' aprofundada na década de $1980^{8}$.

Porém, sem abandonar a retórica de vítima, a partir desses mesmos últimos anos 1980, passaram a ganhar crescente importância no estado as práxis voltadas para espaços

\footnotetext{
${ }^{6}$ Dadas as anotações anteriores, parte desse fenômeno pode, desde logo, ser creditada na conta das referidas centralidade, massa crítica e concentração institucional sediadas no âmbito da antiga capital federal.

${ }^{7}$ Vide sobre esse fato as muitas ações de Getúlio Vargas e, em especial, as de JK terem como foco principal a industrialização verificada desde cedo em São Paulo.

${ }^{8}$ Vide tese de doutoramento de José Luís V. da Cruz (2003), na qual esse autor resgata diversas vozes do antigo estado do Rio afirmando/defendendo, quando da fusão, a responsabilidade da ex-capital/Guanabara com o seu desenvolvimento. Adendo: bradava boa parte da mídia, na sua busca por atribuir o problema crise a outrem (seus adversários políticos), simplista e persecutoriamente, que ela também seria culpa do governante de plantão (no caso, o ex-governador Leonel Brizola).
} 
microrrecortados e/ou as relativas a temas específicos (do estado) numa verdadeira endogenia da análise e da prática. É nessa perspectiva que ganha espaço discursivo e material o chamado Rio Local ${ }^{9}$.

Diversamente: a disjuntiva acima passa a ditar o tom das reflexões e propostas sobre a economia carioca (e mesmo sobre seu desenvolvimento). De outra maneira: respectiva e esquizofrenicamente, as práxis em discussão se moviam de um lado na perspectiva do 'Rio vítima' (que desconsidera escalas 'menores', incluindo a local) e, de outro, na do 'Rio que deveria cuidar de si mesmo' (ignorando escalas 'maiores', como a nacional, por exemplo). Logo, à pobreza e à miséria de parte da população do estado juntavam-se naquele tempo histórico duas equivocadas reflexões de consequências nefastas sobre os rumos da sua economia (e não apenas dela), posto que nenhum lugar é tributário apenas de escalas superiores e, menos ainda nos dias atuais, pode ser considerado uma 'cidadela' (que se esgota em si) ${ }^{10}$.

Isto posto, mister observar com positividade os esforços atuais de busca por uma angulagem histórico-estrutural, com apelos para a necessidade da adoção de uma mirada transescalar, no sentido de explicar e mesmo propor soluções para a complexa crise em que a economia carioca (bem como a fluminense como um todo) mergulhou dramática e manifestamente nos últimos anos, em particular a partir de meados dos anos 2010 - dando seguimento, assim, à sua já secular crise.

À luz do que veio de ser alinhado, visando contribuir com o debate sobre a elaboração de diagnóstico e agenda consequentes para o enfrentamento dos seus graves problemas, sem qualquer isolacionismo escalar, entende-se necessário considerar articuladamente os sujeitos/interesses envolvidos, o que significa não perder de vista os papéis: da academia e da mídia dita especializada (produção reflexiva); dos governos, principalmente o estadual e o federal (federalismo); e das frações do capital atuantes em seu espaço (estrutura econômica). Afinal, não há processo social sem sujeitos sociais.

\footnotetext{
9 Vide as várias iniciativas daquela época chanceladas sob o "label" desenvolvimento local, desenvolvimento local e sustentável, planejamento estratégico de cidade, desenvolvimento endógeno etc. Vale adicionar que esse termo também é tributário, em contraposição, à tese do Rio Nacional (que expressa que os cariocas em geral, bem como suas instituições se ocupariam das grandes questões do país, mas não das que poderiam ser examinadas e enfrentadas nos seus próprios limites político-administrativos).

${ }^{10}$ A esse respeito, vide o excelente livro da Carlos Antônio Brandão (2007) (nas Referências Bibliográficas) e as várias correntes que esse autor, jocosamente, denomina de 'localeiros'.
} 
Para tal, o presente trabalho está estruturado em duas grandes seções, além desta Apresentação e das Considerações Finais, como segue: Seção I. Da problemática expansão econômica do final do século XIX aos 1970, passando pelas duas décadas quase inteiramente regressivas que se seguiram, até as oportunidades perdidas dos anos 19952013; e, Seção II. A gravosa e manifesta crise econômica pós-2014 e o estado das artes do debate atual - diagnósticos e propostas.

Seção I. Da problemática expansão econômica do final do século XIX aos 1970, passando pelas duas décadas quase inteiramente regressivas que se seguiram até as oportunidades perdidas dos anos 1995-2013

\section{Seção I. 1. Da problemática expansão econômica do final do século XIX aos 1970}

Há sobejas indicações analíticas e estatísticas, embora essas últimas não sejam plenamente confiáveis, que a economia carioca era mais importante do que a sua congênere paulista no período que se estende dos 1870 aos anos 1910. Do mesmo modo, também há sobejas referências apontando que a primeira economia foi ultrapassada nos vinte anos subsequentes pela segunda - e largamente.

Ou seja: a economia carioca cresceu e se destacou na cena brasileira desde as três últimas décadas do século retrasado até aproximadamente o ano de 1920. Para esse fim, considerem-se os seguintes fatos: a presença em seus domínios da capital federal e os importantes efeitos-renda derivados da máquina pública nela sediada, assim como, para a época, de uma importante indústria, dos principais porto e praça comercial do País e de um já agigantado terciário ${ }^{11}$. Mas não dá para negar que, desde os 1870, quando do início da instalação da pujante economia mercantil cafeeira em São Paulo, começou a 'florescer' em seus domínios uma indústria moderna, com diversos efeitos de encadeamento para frente e para trás, irreprodutível em qualquer outro espaço nacional, e que, ademais e à larga, ultrapassou nos decênios 1920-30 a primazia da economia carioca no País. Enfim,

\footnotetext{
11 Também cabe assinalar nessa "démarche" a importância da ligação existente entre São Paulo e Rio de Janeiro através da Rede Ferroviária Federal que, em verdade, se estendeu pelo menos até os anos 1940 quando São Paulo, via sistema de cremalheiras, conseguiu galgar a Serra do Mar até Santos (e seu porto). De outra maneira, embora São Paulo tenha ultrapassado largamente a economia carioca, ele continuou nela injetando recursos por conta dessa ligação ferroviária e da anotada importância nacional das praças comercial e financeira (do Rio) até então. Em verdade, a centralidade portuária, comercial e financeira, com temporalidades distintas, avançou para além da passagem do século XIX para o XX - sendo que especialmente essa última chegou até os anos 1970.
} 
era como se a economia paulista, e não apenas industrialmente, passasse a ver a do Rio pelo retrovisor e à distância crescente.

A realidade é que economia paulista afirmou desde cedo relações de complementariedade e especialização com as demais economias regionais, galgando assim o comando da divisão territorial do trabalho (DTT) no País ${ }^{12}$. Não obstante, esse fato tão decisivo é sistematicamente ignorado nas leituras acerca da economia (e desenvolvimento) do Rio (e do estado). Tal desconsideração, vale a ênfase, constitui claro equívoco na medida em que isola analítica e praticamente a economia carioca e fluminense desse macroprocesso e, implicitamente, afora a desconsideração de outras escalas de análise, 'vende' a tese de que a questão regional brasileira - com ironia, por favor - se limitaria ao Norte/Nordeste! Enfim: apesar de não esgotar a discussão, DTT em nível nacional não é assunto para minimizar ou deixar de lado, posto constituir óbice estrutural ao desenvolvimento mais 'equilibrado' do país em sua inteireza.

Por outro lado, em favor dos que cometeram e cometem esses alheamentos, sublinhe-se que a economia carioca, apesar da sua passagem à condição de segunda economia do País, conquanto crescentemente atrás da paulista, não experimentou duradouras quedas da renda e do emprego até a entrada dos anos 1960. É dizer, a economia carioca continuou crescendo, gerando renda e postos de trabalho ancorada que estava: nas rendas advindas do setor público, sobretudo do ente federal; no crescimento da economia nacional, 'puxado' pela paulista; em uma indústria relativamente obsoleta, pouco encadeada e nada competitiva, mas que ainda era a segunda do País ${ }^{13}$; em um terciário que, apesar de precário e assentado em gigantesca informalidade da mão de obra ocupada, apresentava transações econômicas nada desprezíveis; em praças comercial e financeira e num porto e ferrovia (Rede Ferroviária Federal) nacionalmente expressivos em parte importante do período analisado etc. ${ }^{14}$. Ou seja: nas condições dadas, esse crescimento econômico, alguma centralidade espaço-institucional e os aludidos 'pesos' portuário, ferroviário, comercial e financeiro (em seus tempos) foram decisivos para o mascaramento das fragilidades estruturais da economia do Rio.

\footnotetext{
12 Os dois parágrafos anteriores têm como referências as teses doutorais de CARDOSO DE MELLO (1998) e CANO (1977).

${ }^{13}$ Tenha-se em conta neste ponto, mais uma vez, a centralidade financeira do Rio em termos da renda e dos excedentes gerados na economia paulista.

${ }^{14}$ Em complemento, vide segundo parágrafo da página que segue.
} 
Um parêntese em dois parágrafos. Quanto à economia do antigo ERJ, essa 'capotou' já no próprio último quarto do século XIX diante da moderna e competitiva economia cafeeira mercantil de São Paulo. Tal indústria cafeeira (CANO, 1977) foi estruturada, na partida em cima do branco livre assalariado, especialmente o imigrado, de um importante mercado interno (dados os efeitos de encadeamento econômico então suscitados); de modernas técnicas de produção com significativos ganhos de escala; de terras apropriadas para o cultivo do café; e de um sistema de transporte fundamental para a sua dinamização e capacidade exportadora internacional ${ }^{15}$ - tudo ao reverso do que ocorria no antigo Rio (mão de obra escrava, com impactos negativos sobre seu mercado interno; encadeamentos econômicos quase inexistentes; terras inadequadas em qualidade, extensão e topografia; sistema de transporte precário etc.).

Destarte, enquanto a burguesia cafeeira paulista soube se aproveitar dos apoios governamentais da época (câmbio etc.) e do momento extraordinário de expansão da economia mundial (exemplo: o avanço das técnicas de navegação ultramarina em rapidez, segurança e capacidade de armazenamento de mercadorias verificado nos anos 18701930), sua congênere fluminense não se mobilizou em busca das oportunidades ali 'surgidas'. Importante registrar em complemento e nesses termos que a modernização do Porto do Rio de Janeiro não foi acompanhada do avanço pelo encadeamento e complementaridade setorial e espacial da economia da 'região fluminense'. Em suma e no limite, pode-se dizer que a economia cafeeira do antigo estado do Rio 'perdeu o pé antes mesmo da sua entrada no século XX.

Voltando à economia carioca. Como apontado, ela seguiu se expandindo... afora os aspectos antes listados, isso ocorreu ainda por conta do cenário internacional favorável graças às 'reservas de mercado' dos anos 1910 (1 $1^{\text {a }}$ Guerra Mundial), 1930 (Grande Depressão), 1940 (2ª Guerra Mundial) e parte dos 1950 (Plano Marshall) e, em seguida, pelo avultado crescimento econômico promovido na esteira da implementação do Plano de Metas do governo JK (1956-61). Ou seja: com a economia se expandindo, em que pese à problemática urbanização que se gestava em seus domínios (FARIA, 1991), os problemas estruturais, em especial os da sua economia, continuaram sendo subestimados... afinal, a renda e o emprego cresciam, e o 'Estado era (?) do Rio'!

\footnotetext{
${ }^{15}$ Vide SILVA, S. (1976).
} 
Na entrada dos 1960, em concomitância histórica, dois fatos acenderam uma primeira luz de alerta: a crise econômica nacional dos anos 1960-67, que por suposto incidiu negativamente sobre as economias estaduais e, em simultâneo, a visível discrepância existente entre a estrutura econômica paulista, principalmente no que trata da dimensão industrial e tecnológica, vis à vis à carioca (dados sobretudo os investimentos da era JK).

Foi exatamente nesse contexto que entrou em cena, com efetiva força discursiva e pretensão de diagnóstico, o lamento sobre as dívidas do governo central para com a excapital por conta da sua transferência para Brasília. Vale observar que essa tese foi reforçada na medida em que, exatamente naquele contexto, a economia carioca (junto com a nacional, reitere-se) entrou em crise - depois do sucesso espetacular da segunda metade dos anos 1950. Adiante (1970), embora em contexto de crescimento econômico, por conta da decisão arbitrária do regime militar em fazer a fusão antes referida, o 'ego carioca ferido e não cicatrizado' pela transferência da capital novamente brandiu a tesediagnóstico das perdas, registrando-as mais uma vez nas contas da União/do governo federal.

Ora, dizer que esses eventos repercutiram negativamente sobre a economia fluminense em geral e, em particular, sobre a da antiga capital é acaciano; todavia, atribuir-lhes a culpa pela crise econômica é um erro, posto que ela é historicamente longeva (como já se defendeu). Mais: se é verdade que essa crise não pode ser afastada da sua complexa relação com o Poder Central, tampouco pode sê-lo da mencionada DTT em nível nacional, das forças econômicas e políticas que comandaram desde cedo as escolhas estratégicas acerca do desenvolvimento econômico da 'região fluminense' e da chancela - falsa - de boa performance econômica concedida pela dita mídia especializada - e porque não dizer por conta da ausência de uma crítica-acadêmica rigorosa e tonitruante acerca dos seus graves problemas estruturais ${ }^{16}$.

Mas essa saga de descaminhos não parou por aí. Nos anos do 'Milagre Econômico’ (1968-73) e do crescimento econômico nacional promovido pelo II Plano

\footnotetext{
${ }^{16}$ É trivial que também participa desse processo o processo de formação do empresariado carioca e do paulista, posto que 'constituídos', em regra, de maneira distinta. De forma um tanto caricata, pode-se dizer que, enquanto o último o foi em um ambiente mais apropriadamente capitalista (não obstante traços históricos tão peculiares da formação social brasileira, como o são o clientelismo, o compadrio etc.), o primeiro, o carioca, se deu definitivamente imerso nos referidos 'atavismos' (cliente/fornecedor do Estado, tutelado e imbricado em redes de trocas-favores-assistência-clientela).
} 
Nacional de Desenvolvimento do governo Geisel (1974-1979), a insensatez carioca/fluminense continuou em marcha (CASTRO e SOUZA, 1985; LESSA, 1978). Em síntese: a agenda da crise logo saiu de cena, evidenciando que, para alguns analistas, o conceito de 'boa performance econômica' se reduziria à mera expansão da renda e do emprego, esquecendo-se (eles) de observar, quiçá por desconhecimento ${ }^{17}$, a essencialidade da dinâmica e natureza do processo de acumulação de capital, dos encadeamentos produtivos, da capacidade competitiva da indústria em questão e das formas disponíveis (ou não) para o financiamento da sua modernização tecnológica etc. - o que, fosse feito, teria desvelado o quão 'atrasada', especialmente em termos relacionais, era a economia carioca e, em especial, a antiga economia fluminense...

É dizer: passaram-se cerca de cento e vinte anos sem que a produção reflexiva 'local' apontasse, com clareza, as fragilidades estruturais da economia da 'região, especialmente a industrial - sendo que não fora bastante esse diagnóstico poderia ter sido feito inclusive em perspectiva histórica e interescalar, posto haver estatísticas e informações disponíveis confiáveis; sem que as frações de classe predominantes do capital também o fizessem, possivelmente porque os principais grupos empresariais sediados em seus espaços - da indústria naval, do setor financeiro, do grande comércio etc. - nada tinham do que reclamar (seus mercados eram lucrativos e, provavelmente, seus jogos patrimoniais junto aos governos estadual e federal operavam a contento); e, sem que a chamada classe política, enquanto representação dos 'interesses do ERJ', 'percebesse' que as 'coisas' não estavam indo bem - possivelmente por supor que o crescimento da renda.

E, no caso do Rio, além deste fato, pela presença da máquina pública em seu território (por quase todo o período em análise) eram de "per se" garantias de sucesso! Esse lamentável estado das artes do saber, da estrutura econômica e da prática política não poderia senão agravar antigos problemas, bem como a eles adicionar, no tempo e cumulativamente, outros tantos...como se mostrará adiante.

\footnotetext{
17 Infelizmente, sem a devida formação teórica muitos economistas tornam-se especialistas apenas em análise de conjuntura, o que, não obstante a sua importância, tende a levar a perda de vista dos processos mais recônditos e essenciais da marcha da história e dos sujeitos sociais que os empalmam!
} 


\section{Seção I.2: Das décadas econômicas quase inteiramente regressivas (1980s-90s) até as oportunidades desprezadas dos anos 1995-2013}

É sabido que houve no País, nos anos 1980, queda pronunciada da renda nacional. No Rio, a crise econômica foi monumental. Foi então que, nele, finalmente, luzes vermelhas se acenderam. Nesse decênio, que economistas denominaram de a 'década econômica perdida', as fragilidades estruturais da economia fluminense e carioca foram mais amplamente percebidas. Dentre outras mazelas, ficou nítido que havia: uma estrutura industrial obsoleta em si, quando comparada com a paulista e mais ainda com a das economias centrais (posto terem elas 'saltado' para a Terceira Revolução Científica e Tecnológica); um gigantesco e precário terciário, com significativa informalidade da mão de obra ocupada, gerador de expressivos desdobramentos negativos sobre a chamada rede de proteção social, bem como incapaz de produzir a massa necessária de rendimentos para dinamizar mais efetiva e duradouramente a economia; um desemprego generalizado, sem maiores colchões amortecedores para sustentar a renda estadual; uma queda aguda dos rendimentos do trabalho etc. - para não falar da crise social expressa no aumento da violência urbana, na mendicância; uma economia agropecuária em franco descenso no interior do estado e, em alguns casos, inteiramente colapsadas (vide a economia sucroalcooleira do Norte do estado, que foi sepultada com a extinção do Instituto do Açúcar e do Álcool e com a crise do Proálcool, assim como a crise da agropecuária leiteira e da indústria de laticínios) ${ }^{18}$; etc.

Por conseguinte, foi preciso chegar à década de 1980 para se tomar alguma consciência acerca da gravidade da situação. Ex.: do significado problemático (para o País) da DTT nacional capitaneada por São Paulo desde a entrada do século XX; da necessidade de enquadrar nos seus devidos lugares ${ }^{19}$ os eventos transferência da capital e

\footnotetext{
${ }^{18} \mathrm{O}$ processo de modernização do segmento sucroalcooleiro nacional contemplou São Paulo (SP) como estado privilegiado por várias razões, a saber: as políticas, as tecnológicas e as da iniciativa empresarial. Com o Proálcool, SP se distancia do ERJ e polariza a indústria nacional. Razões inerentes à implantação do Proálcool no ERJ (recursos, defasagem entre investimentos na indústria e na lavoura, dentre outros) e à transferência de recursos dos diversos fundos públicos federais não foram suficientes para estancar a crise no Norte e Noroeste fluminense.

${ }^{19}$ Ressalvem-se aí o início da produção de petróleo na Bacia de Campos, no Norte do estado, em 1978, que, ao final dos anos 1980, já representava mais da metade da produção nacional; e o início das transferências, aos municípios e ao estado, relativas aos royalties da produção petrolífera a partir de 1986 - embora pouco relevantes até 1998.
} 
fusão; da urgência em buscar soluções mais estruturais para a economia do estado (e seu desenvolvimento como um todo); etc.

No entanto, infelizmente, mais uma vez predominaram o escapismo dos agentes econômicos e governos locais, a reiteração das lamentações (por conta da perda da tutela e do patrimonialismo/clientelismo históricos que sustentaram anos a fio a economia da 'região') e a precariedade reflexiva (e prática) acerca dos seus problemas econômicos - e vale reiterar: tudo isso chancelado pela maior parte da produção acadêmica e midiática sobre a economia e sociedade carioca/fluminense. Em síntese: as razões de fundo foram varridas para debaixo do tapete, empurrando-se para frente a produção de um diagnóstico consoante à gravidade histórica da economia (e da sociedade) carioca e mesmo da fluminense como um todo.

E assim o foi nos anos 1990 com a chegada de Collor de Mello ao poder e, adiante, Fernando Henrique Cardoso e suas agendas neoliberais. Nesse contexto, passaram a ecoar as seguintes teses: o mundo mudara e, desse modo, seria preciso 'descolar do Estado' e saudar uma nova via de desenvolvimento - a que seria 'tocada' pela chamada iniciativa privada (como se o recuo do Estado viesse a ser compensado automaticamente pelos investimentos privados) ${ }^{20}$; em simultâneo, defendia-se que, nesses 'novos tempos', os anotados investimentos privados, especialmente os estrangeiros, não poderiam senão contemplar o espaço do Rio como uma das principais sedes das suas aplicações; e, por fim, enquanto desdobramento, que os novos investimentos, em especial os mais eivados de modernas tecnologias, confirmariam o destino do Rio enquanto capital tecnológica por excelência do País (dizia-se que isso era o que importava, dado o caráter não poluidor dessas novas indústrias) ${ }^{21}$.

Passada essa década, constatou-se o óbvio: nas condições dadas da economia e da política brasileira, bem como das estratégias locacionais/de mercado das grandes empresas internacionais, o destino privilegiado dos novos investimentos não foi o ERJ, e sim São Paulo. Ou seja: conquanto passasse a ser a sede da gestão de algumas empresas

\footnotetext{
${ }^{20}$ Como aliás voltou a ser brandido nos governos Temer e Bolsonaro!

${ }^{21}$ Vale anotar neste ponto que a Federação das Indústrias do Rio de Janeiro (FIRJAN) apresenta nesse tempo histórico composição bastante heterogênea em vista da antiga Federação das Indústrias do Estado da Guanabara (FIEG). Indo ao ponto: muitos empresários abrigados na nova sigla a bem da verdade se mostravam afastados das atividades produtivas propriamente ditas. De maneira mais precisa: seus ganhos eram (e continuam sendo) sobretudo obtidos através das suas aplicações no chamado mercado financeiro passaram, enfim, a serem 'sócios menores' do rentismo e do neoliberalismo financeirizado tão marcado pela ascensão ao poder do senhor Fernando Henrique Cardoso.
} 
que se instalaram no País por força das privatizações de então, o estado recebeu poucos investimentos industriais - com as exceções de montadoras automobilísticas no Médio Vale do Paraíba Fluminense (MVPF) (Volkswagen etc.) e de uma empresa siderúrgica incontroversamente poluidora - em Santa Cruz (bairro do município do Rio) ${ }^{22}$.

Por outro lado, as notícias ruins para a economia fluminense continuaram se sucedendo. Ilustrando, vide: as privatizações de ativos públicos, como ocorreu com a Companhia Siderúrgica Nacional, que elevou o nível de desemprego no MVPF, dadas as demissões em massa que logo foram promovidas $^{23}$; os processos de privatização de então, que, no afã de adequação às novas formas de gestão, além do desemprego gerado, levaram à precarização da força de trabalho contratada para os chamados serviços gerais; mais: que, no bojo desse mesmo processo, foram comprimidos os rendimentos do trabalho das apontadas funções mais especializadas e, consequentemente, como antes, a demanda da economia; ainda: que seu impacto positivo imediato em termos de geração de postos de trabalho se concentrou nas empresas demandantes de profissionais altamente qualificados (mas que sabidamente não são "labor intensive") etc. Em resumo: lá se foi outra década econômica perdida - ou seja: 130 anos de degradação/falta de um rumo consequente!

E tudo isso legitimado pelas 'vozes do Rio', que, com força hegemônica, consorciadas em sua maioria com o 'deus mercado', nunca ouviram ou mesmo permitiram que as vozes dissonantes existentes (ainda que poucas) verbalizassem e propusessem soluções alternativas acerca dos agudos e estruturais problemas da economia e da sociedade carioca (e fluminense) ...

No entanto, na segunda metade desses mesmos 1990, a economia fluminense, comparada com ela mesmo no tempo, em especial com os anos 1980 e o primeiro quinquênio da década subsequente, apresentou o que ficou nomeado pelo primeiro autor deste ensaio em escritos anteriores de inflexão econômica positiva. Ou seja, por uma série de razões (atração de empresas via guerra fiscal, aumento das receitas derivadas dos royalties do petróleo, alguns investimentos privados, maior capacidade tecnológica do capital produtivo de espraiamento territorial etc.), houve ali uma dada mudança positiva

\footnotetext{
${ }^{22}$ Montadoras automobilísticas: às margens da Rodovia Presidente Dutra, com estratégias mais ligadas ao mercado existente no estado de São Paulo; Siderúrgica: Companhia Siderúrgica do Atlântico (CSA); e, Telefonia: TIM, TELEMAR, OI/TNC PCS.

${ }^{23}$ Há análises que sugerem que com essa privatização a empresa passou a operar, dada a elevação extraordinária da intensidade do trabalho promovida, com cerca de $1 / 3$ dos quadros antes existentes.
} 
de performance em relação à trajetória de degradação econômica imediatamente precedente.

Passo seguinte, em parte dos anos 2000-13 ${ }^{24}$, essa inflexão se fez seguir de uma espécie de 'milagrinho econômico' (em coro com a cena nacional). Ele pode ser ilustrado pela importância econômica em si da cadeia de petróleo e gás, bem como pelo seu impacto sobre a indústria naval. Acrescente-se na composição desse quadro: o começo da construção do Complexo Petroquímico do Estado do Rio de Janeiro (COMPERJ); o início das obras de duplicação da subida da serra de Petrópolis ${ }^{25}$; a construção (e entrega) de uma das alças do Arco Rodoviário Metropolitano (Rio Petrópolis-Itaguaí) e o começo das obras na outra alça (a que ligaria a Rio-Teresópolis à Manilha e dali até São João da Barra); a realização de diversas obras por conta dos grandes eventos esportivos de então (Olimpíadas, Copa do Mundo etc.); a construção de novas fábricas de automóveis no Médio Vale do Paraíba; a construção de terminais portuários; o salto vertiginoso do volume de royalties e participações especiais decorrentes da Lei do Petróleo; os novos investimentos industriais no Norte Fluminense, em decorrência da quebra do monopólio estatal de Exploração e Produção de petróleo e gás, e o "boom” relativo da indústria naval; e, por fim, as obras também iniciadas no Porto de Itaguaí, no Porto do Açu etc) ${ }^{26}$. Em suma, o ERJ foi bem contemplado em termos de investimentos, particularmente em infraestrutura de circulação de mercadorias, e para tal 'salto' histórico imprescindível sublinhar o papel decisivo dos PAC I e PAC II (Programa de Aceleração do Crescimento I e II) do governo federal.

De outra forma: sobretudo nesse último intervalo de tempo, tendo em vista o que veio de ser arrolado, houve importante oportunidade para a realização de esforços orientados no sentido da reversão da trajetória de crise econômica longeva analisada neste ensaio, dados pelo menos três fatos cruciais (além dos fenômenos antes citados): a elevação da cotação do barril do petróleo no mercado internacional, que injetou massa

\footnotetext{
${ }^{24}$ Isso ocorreu principalmente nos governos Lula II e Dilma I.

${ }^{25}$ Obra atualmente paralisada - desde 2016.

${ }^{26} \mathrm{O}$ ERJ, com seus mais de $800 \mathrm{~km}$ de costa, possui atualmente (2021) diversos portos em operação, como são os do Açu (operando a partir de 2014), de Itaguaí (operando a partir de 1982) e do Rio de Janeiro. Também vale registrar: a expansão do terminal portuário da Baía de Sepetiba e os novos terminais dos portos Sudeste e PROSUB (Programa de Desenvolvimento do Submarino da Marinha). Registre-se ainda os diferentes terminais portuários de apoio "off shore” de Niterói e do Rio, na Baía da Guanabara. Ressaltese aqui os projetos e os esforços de implantação de indústrias nas suas retroáreas e áreas de influência conforme o modelo porto-indústria (ver PESSANHA, 2017).
} 
nada desprezível de recursos no país e, claro, na economia fluminense; a aliança política estabelecida entre os governos municipal do Rio, estadual e federal, que sabidamente implicou, naquela conjuntura, em aumentos significativos de aporte de recursos do governo central aos domínios territoriais fluminenses; e, é trivial, o crescimento econômico do País na esteira do que se denominou de 'milagrinho' brasileiro (CARVALHO, 2018).

Nesses termos, resultou: notória a necessidade do ente federal para 0 desenvolvimento do ERJ; o potencial de crescimento da 'região' em tela quando as esferas municipais (principalmente do município-sede) e estadual, bem como as áreas de infraestrutura e petróleo e gás são alcançadas positivamente ${ }^{27}$; a identificação de alguns 'pontos fracos', como o são os da estrutura industrial, das finanças públicas; e a ausência de diagnósticos e propostas de políticas públicas mais consoantes às necessidade da economia e do desenvolvimento fluminense na sua integralidade.

No entanto, quer da academia, quer dos governos estaduais do período, e tampouco dos setores empresariais, partiu uma 'leitura abrangente' que sublinhasse as possibilidades ali existentes, de sorte a sustar os aproximados 130 anos anteriores de degradação estrutural ${ }^{28}$. Não fora suficiente, nova crise econômica nacional logo se impôs, obstando esse processo potencialmente auspicioso.

Complemento importante: entende-se que o indispensável recurso a séries históricas temporais de maneira a reforçar a tese (verdadeira) da crise econômica longevoestrutural fluminense acabou por contribuir perversamente para 'evaporar' os supramencionados milagrinho e inflexão e, assim sendo, para dificultar a devida apreensão das possibilidades posicionadas naquele tempo no que tange à elaboração de um diagnóstico mais abalizado sobre a sua economia, a consequente adoção de adequadas políticas públicas e o estabelecimento dos devidos contenciosos federativos!

\footnotetext{
27 Como já apontado, daí a necessidade de pensar transescalarmente o temário da economia e do desenvolvimento do estado do Rio...

${ }^{28}$ A exceção, mesmo assim limitada, ficou por conta da alusão à economia petrolífera, com suas rendas adicionadas aos orçamentos que por si só alavancariam a economia estadual/“regional”.
} 


\section{Seção II. A gravosa e manifesta crise econômica pós 2013-14 e o estado das artes do debate atual - diagnósticos e propostas}

Por volta dos anos 2013-2014, a euforia fluminense e seu canteiro de obras já davam indícios de reversão; de certa maneira, o evento Copa do Mundo foi a última página do 'milagrinho' do Rio ${ }^{29}$.

A partir daí, praticamente tudo foi revertido. Exemplificando: houve expressiva retração na cotação internacional do barril do petróleo, bem como início do ciclo descendente da produção dos campos maduros da Bacia de Campos, com negativos e sérios impactos sobre o repasse de royalties para os cerca de 2/3 dos municípios do estado que recebem esses recursos (e para o próprio estado, é trivial); com a crise econômica nacional e o ajuste fiscal então reforçado pelo governo federal (CARVALHO 2018), os repasses em geral e para a unidade federativa em análise também foram contraídos; com essa mesma crise econômica, igualmente foi reduzido o repasse do ICMS (Imposto sobre Circulação de Mercadorias e Serviços), que, como se sabe, representa a maior parte dos recursos tributários arrecadados no País (cerca de 51\% do total) e está umbilicalmente ligado ao nível geral da atividade econômica - logo, com graves e perversos desdobramentos sobre a economia brasileira em geral e, no caso, sobre a do estado do Rio e sua capital; adicionem-se os generosos subsídios concedidos ao setor privado pelo governo do ERJ, que agravaram sua situação fiscal ${ }^{30}$; a paralisia generalizada das obras públicas em curso no estado, como a da subida da serra de Petrópolis, a da segunda alça do Arco Rodoviário Metropolitano etc., com perversos efeitos, dentre outros, sobre o nível de emprego da população fluminense; os efeitos também negativos da Operação Lava Jato, uma vez que ela impossibilitou uma série de gastos de empresas importantes, como o são a Petrobras, grandes empreiteiras de obras etc.; o fim da política de conteúdo local, no governo Temer, relativa ao setor do petróleo e que contribuía de maneira positiva para os tão reclamados encadeamentos produtivos (com reflexos negativos na cadeia industrial, como a indústria naval e os projetos de petroquímica e infraestrutura); queda pronunciada da renda e do emprego desencadeada pela crise nacional e pela estadual propriamente dita etc.

\footnotetext{
${ }^{29}$ Expressão retirada de Laura Carvalho (vide referências bibliográficas) e orientada ao âmbito nacional, especialmente ao período Lula II e aqui, por analogia, empregada.

${ }^{30}$ Não obstante os seus valores exatos sejam controversos, posto haver divergências técnicas acerca dos números divulgados pelo Tribunal de Contas do Estado do Rio de Janeiro, TCE-RJ.
} 
Nesse contexto, em perspectiva histórica, com o destaque da exceção de real possibilidade de superação dos seus 'atávicos' problemas estruturais logo antes apontada, a economia fluminense apenas conheceu crise (estrutural) em seus últimos aproximados 140-50 anos - vale repetir: mesmo quando a renda e o emprego aumentaram, e tendo ou não a capital federal nos limites territoriais carioca.

Diante desse quadro, cabe recuperar e analisar mais amiúde as teses/defesas que circulam no mercado da produção reflexiva sobre a crise econômica do Rio. Para esse propósito, o que segue nesta seção foi estruturado em três itens: A) Encaminhamentos Metodológicos; B) Diagnósticos; e C) Propostas.

\section{A) ENCAMINHAMENTOS METODOLÓGICOS}

Dois aspectos devem ser aqui enfatizados, a saber: 1) A crise econômica seria longevo-estrutural e o 'laboratório' de possibilidades dos anos 1995-2013; e 2) A crise econômica exigiria um olhar acerca das especificidades do ERJ e, em particular, sobre a cidade do Rio, bem como da sua indissociabilidade com os temas da transescalaridade e do federalismo. Como segue:

1) A crise econômica seria estrutural e longeva. Cabe retomar aqui a inflexão econômica positiva de meados dos anos 1990 e o crescimento que se seguiu com o 'milagrinho' fluminense, posto entender-se que esses eventos não devem ser sempre 'evaporados' nas chamadas séries temporais (à guisa de ilustração, vale registrar que, até 2014, o ERJ foi o epicentro da indústria de petróleo e gás brasileira). Sem discordar da tese de crise estrutural longeva da economia fluminense, como já se analisou, reiterando, defende-se que houve nesses anos uma mudança na trajetória do crescimento econômico do ERJ (insista-se: quando comparado com ele mesmo no tempo apontado) e que ela deve ser destacada - e não ignorada ou minimizada. Mais importante: ela deve ser destacada porque esses momentos transcenderam taxas, comparações nacionais e remissões a séries históricas na medida em que o que verdadeiramente importa é que ocorreu ali um momento/‘laboratório’ extraordinário para a produção de um diagnóstico e elaboração de políticas públicas verdadeiramente consequentes para efeito da reversão de mais de um século de estiolamento econômico (em verdade, não apenas econômico) do conjunto da área hoje definida como estado do Rio de Janeiro. 
Como já se apontou, entende-se que esse período é crucial para o desvelamento dos problemas a serem enfrentados, uma vez que foram então realizados investimentos de mobilidade urbana, infraestrutura e alguns diretamente relacionados à cadeia de petróleo e gás, assim como estabelecidas alianças políticas intergovernamentais proativas, bem como é trivial, tornados mais claros os obstáculos a superar (vide especialmente os itens B e C) - e tudo isso em um contexto de adoção de políticas de corte keynesiano (que ainda contou com um cenário externo favorável).

2) A crise econômica exigiria um olhar acerca das especificidades do estado e, em particular, sobre a cidade do Rio, bem como da sua indissociabilidade com os temas da transescalaridade e do federalismo ${ }^{31}$. O termo especificidade sugere que as análises devam focar centralmente nas estruturas econômicas existentes no espaço fluminense. Nada a discordar quanto a esse 'encaminhamento'; ou seja, o de partir delas para efeito da análise e formulação de propostas concernentes ao seu desenvolvimento. No entanto, cumpre chamar atenção que o foco nas aludidas especificidades (que existem) não pode ser confundido com o desprezo pela consideração das escalas maiores, em especial a do País, incluindo-se aí: os contenciosos a serem estabelecidos no plano nacional e, especialmente, com o governo federal no que trata da cobrança do ICMS do petróleo e gás no destino (e não na origem); a necessária e urgente discussão da mãe de todas as reformas, a tributária, para fins da obtenção de recursos capazes de alargar os horizontes das políticas públicas etc. De maneira diversa: focar no ERJ a partir das suas especificidades não pode alhear as disputas federativas, tanto mais se entenda que o seu desenvolvimento exige a consideração do ente federal - e mesmo de outras escalas menores, mas superiores à escala local...

\section{B) DIAGNÓSTICOS}

Para melhor apreciação, entende-se importante discriminá-los em três blocos, a saber:

1. Bloco dos diagnósticos escapistas, mas que não devem ser ignorados liminarmente.

\footnotetext{
${ }^{31}$ Um reparo: entende-se aqui mais adequado o emprego do termo geral singularidade (em vez de especificidade), por duas e principais razões: uma, derivada do fato de o ex-distrito federal ter sido capital por quase duzentos anos, fato único no Brasil e, por causa, deixado marcas profundas na estrutura socioeconômica do estado; e a outra, associadamente, pelo fato de essa economia ter se desenvolvido por cerca de cem anos em vista do primeiro considerando e do próprio crescimento do País (largamente tributário do crescimento da economia paulista) - e que, assim sendo, não pode ser menosprezada em termos nacionais... apesar dos pesares.
} 
1.1) A crise econômica seria derivada das perdas do Rio com a transferência da capital para Brasília. Entende-se que é preciso colocar tal evento definitivamente em seu devido lugar. Afinal, dizer que ele impactou de maneira negativa sobre a sociedade fluminense e, em especial, a economia do estado, não equivale a entendê-lo fundamente para a explicação da crise estrutural em exame (como se fosse uma maldição "ad infinitum"). Logo, na presente contemporaneidade, a 'mirada sobre Brasília' deve deixar de lado esse evento e se concentrar em problemas contemporâneos e urgentes - vide, por exemplo, o caso do ICMS (antes anotado); o do REPETRO (Regime Aduaneiro Especial de Exportação e Importação) ${ }^{32}$; o da indispensável rejeição às políticas neoliberais, posto que elas apenas produzem crise econômica, queda da arrecadação e dos repasses tributários; o da rediscussão do pacto federativo etc.

1.2) A crise econômica seria não apenas advinda da fusão, como dos problemas que ela implicou no entorno metropolitano carioca. Como no item anterior, entende-se que esse evento não pode ser invocado como explicação causal da crise econômica do estado, posto que ela lhe antecede no tempo - como já foi sobejamente analisado. Afinal, como antes, uma coisa é dizer que o evento em questão provocou perdas econômicas - no curto e médio prazo -, e outra é atribuir-lhe a importância em questão (vale destacar aqui que durante duas décadas, pelo menos, a economia petrolífera do Norte do estado rendeu bilhões de reais aos cofres do estado e da região em tela). No que trata especificamente do entorno metropolitano, vale lembrar que esse espaço já era degradado desde o final dos ciclos agrícolas da passagem do século retrasado para o passado (como o da laranja, por exemplo, bastante presente no gigante município de Nova Iguaçu de antes das emancipações dos anos 1990 - a esse respeito, vide Oliveira, 2010); da sua histórica secundarização econômica pelo ex-distrito federal e atual capital do ERJ, manifesta na megacefalia dessa fração territorial no seu âmbito regional e mesmo estadual; do preço atrativo das suas terras que, assim sendo, atraíram para seus domínios uma população de limitado poder aquisitivo e muitos migrantes nordestinos, conformando uma ocupação social segregada típica da baixa renda (incluindo-se aí os direitos sociais básicos); do

\footnotetext{
32 Tal Regime legisla sobre a suspensão da cobrança de tributos federais na importação de equipamentos para o setor de petróleo e gás. A disputa nele envolvida diz respeito ao fato de alguns entenderem que essa suspensão seria benéfica, pois atuaria enquanto elemento de atratividade de investimentos, ao passo que outros entendem que ele prejudica as contas públicas/arrecadação, ainda mais em tempos de crise econômica. A esse respeito, vide o Portal G1, de 23.03.2018, intitulada "Lei que pode alterar o Repetro é debatida em audiência pública na Câmara de Rio das Ostras, no RJ”.
} 
mandonismo do tipo coronelista vigente em seus espaços de longa data, com sérios rebatimentos sociopolíticos; etc...

Assim sendo, se é para trazer à baila a questão metropolitana (e ela deve sê-lo), melhor perseguir outras discussões, tais como a da histórica megacefalia do municípiosede, a ausência de fóruns e instâncias governamentais de gestão metropolitana, bem como de fundos específicos para o chamado desenvolvimento regional etc. Por outro lado (e por fim), anote-se que, não obstante os reparos anteriores, mister reconhecer que os objetivos iniciais da fusão não foram mesmo alcançados e que é preciso retomar essa temática urgentemente visando concluí-la para efeito da promoção de um desenvolvimento mais integrado do conjunto do estado. Afinal, o ERJ não rompeu a dicotomia capital/metrópole-interior, não desenvolveu uma estrutura e aparelhos de planejamento e integração territorial, e pior, ainda não se constituiu para valer em termos identitários, político-administrativos, e de planejamento e de desenho e implementação de políticas públicas integradas e integrativas.

2. Bloco dos diagnósticos que contribuem em maior grau para a explicação.

2.1) A crise econômica seria o resultado da má gestão, dos efeitos nefastos da Lava Jato e da farra dos subsídios. Este ensaio reconhece que os problemas correntes da economia fluminense guardam relação com os efeitos perversos alinhados, mas defende mais uma vez que aqueles transcendem a esses últimos. É dizer que, embora tenha havido dada farra fiscal (em especial no governo Sérgio Cabral), sérios danos sobre a economia do estado por conta da referida Lava Jato (notadamente nos negócios relativos às empresas de engenharia, e de petróleo e gás, dentre outras) e recorrente má gestão (seja em termos de eficiência, seja em termos de eficácia) não devem ser atribuídos a esses aspectos de caráter fundante. De qualquer maneira, forçoso reconhecer que seus malefícios não podem ser olvidados na elaboração de um consequente diagnóstico e na formulação das devidas políticas públicas orientadas para o seu desenvolvimento. É dizer que esse desenvolvimento passa pela questão fiscal (gravíssima); pela realização dos investimentos das aludidas empresas em seus domínios; e pela busca de uma gestão efetivamente republicana e comprometida com o desenvolvimento sustentado e sustentável do ERJ. 
2.2) A crise econômica (e da própria sociedade fluminense) seria devido à falta de instituições adequadas. Amparada no economista Douglas North ${ }^{33}$, essa tese diagnostica que o ERJ, notadamente a sua capital, por razões históricas diversas (o golpe políticomilitar de 1964, que retirou arbitrariamente da vida pública uma série de inteligências; o tamanho do aparelho de Estado, que inibiu o aparecimento ou o avanço das instituições da sociedade civil; etc.), apresenta/constituiu instituições frágeis - processo esse que alcançou gravosamente as dedicadas ao estudo e à formulação de propostas concernentes ao desenvolvimento fluminense.

Sublinhe-se que os autores deste ensaio reconhecem a importância das instituições na vida societária de qualquer recorte geográfico/político-administrativo, mas que igualmente entendem que tal recurso, o da consideração das fragilidades institucionais do estado, o que é inteiramente procedente, não pode deixar de lado os sujeitos políticos e econômicos, que dão sentido à formação social em exame (como apontado, seja ela qual for), e suas instituições. Sendo assim, no caso concreto, parece mais pertinente se perguntar o porquê de eles, com exceções, não terem dado importância aos centros de pesquisa e à produção de conhecimento sobre o ERJ - afinal, qualquer analista bem aparelhado intelectualmente sabe que elas não pairam abstratamente sobre as relações econômicas e de poder.

3. Bloco dos diagnósticos verdadeiramente explicativos.

3.1) A crise econômica derivaria da falta de uma estrutura produtiva encadeada e competitiva. Tal tese vai ao encontro do que se alinhou na primeira seção. Vale dizer: a estrutura industrial fluminense é desde sempre frágil e pouco encadeada. E isso, tal como acontece no âmbito do País como um todo, estiola qualquer projeto de expansão econômica mais sustentada no tempo na medida em que implica o agravamento das contas externas e/ou a migração de renda para outras localidades - no âmbito nacional, notadamente para São Paulo. Por conseguinte, mister identificar as indústrias e cadeias

\footnotetext{
33 Douglas North (1920-2015), economista estadunidense, é considerado um dos fundadores da chamada nova economia institucional. Nela, ele defende que as instituições seriam restrições humanamente concebidas para efeito da estruturação das interações políticas, econômicas e sociais, cujo objetivo visaria a promoção do crescimento econômico. Para esse autor, com as instituições, estariam garantidas a propriedade privada e a redução dos chamados custos de transação e, por consequência, o aumento do crescimento da renda. Embora pertencente à escola neoclássica de economia, ele rejeitava o suposto da racionalidade dos agentes econômicos (tão caro à tradição teórica neoclássica), sem deixar de mencionar que a ideologia não estava à margem na formulação dos economistas.
} 
produtivas a valorar para o soerguimento sustentado da economia do estado, sabendo-se de antemão que pelo menos duas delas são cruciais: a de petróleo e gás e a relativa à infraestrutura (neste caso, dada a existência de importantes empresas de engenharia pesada no País, apesar de combalidas pela ação deletéria da Lava Jato sobre elas). Além disso, há a possibilidade de explorar indústrias outras que se relacionam com as demandas mais urgentes da população, como as da moradia, saúde etc. - que, tal é o 'déficit' existente nessas áreas, abririam mais frentes de expansão econômica e de geração de emprego. Ou seja, demanda-se uma ação planejada, baseada nas características, na história e nas práticas econômicas do estado em toda a sua diversidade ${ }^{34}$.

3.2) A crise econômica seria a resultante dos graves problemas fiscais existentes. Esta tese é um dos pilares para a discussão sobre o desenvolvimento sustentado da economia fluminense e do próprio estado como um todo. Nesses termos, cumpre examinar quais são os problemas tributários e, em plano mais geral, fiscais do ERJ. Alguns já foram assinalados (REPETRO e ICMS sobre o petróleo e gás no destino) e outros devem ser arrolados, como o dos passivos da União com os governos estaduais por conta da chamada Lei Kandir, a distribuição dos royalties no País e os termos recentes da denominada recuperação fiscal do estado vinculada, que foi ao corte dos gastos públicos e à venda do patrimônio público etc. Impõem-se, então, a necessidade da rediscussão do pacto federativo, com destaque para os mecanismos fiscais de financiamento do desenvolvimento dos estados e municípios (incluindo aí os tributários, marcados por uma estrutura regressiva, que impede o aumento da arrecadação), bem como a discussão soberana da política econômica em curso no País (aliás, de longa data), posto que ela é contrária à geração de renda, à criação 'a maior' de emprego e ao aumento da arrecadação...

\footnotetext{
${ }^{34}$ Vide, ilustrando, os atuais nichos de produção de cachaça espalhados por todo o estado - com parte da produção exportada; o reerguimento da produção cafeeira no Noroeste do estado, com base em cafés selecionados, gourmet e da agroecologia - também com parte da sua produção já exportada; a produção agroindustrial de diversos assentamentos rurais; etc.
} 


\section{C) PROPOSTAS}

No que tange às propostas, elas são referidas aos seguintes eixos (complementares), como segue: 1) estrutura produtiva; 2) finanças públicas; 3) dimensão espacial (do desenvolvimento); 4) lutas federativas; e 5) produção reflexiva e gestão governamental.

\section{1) O eixo estrutura produtiva}

Partindo da tese de que a estrutura industrial do ERJ é competitivamente frágil e pouco encadeada, este eixo deve ser considerado sob dupla angulagem: enquanto vetor de dinamização econômica de "per se" e suporte para o crescimento da renda e emprego. Sob a primeira perspectiva, tendo em vista os grandes mestres da boa teoria econômica (Keynes (1971), Kalecki (1977), Schumpeter (1982), etc.), resulta trivial que o investimento é basilar para a dinamização da economia. É dizer, conquanto implique aumento potencial da oferta na economia, dada a capacidade instalada que gera, o investimento é essencialmente propulsor/demandante da produção de máquinas e equipamentos (os chamados efeitos para frente e para trás cumprem aqui papel crucial para a ativação da economia). Já no que concerne à segunda perspectiva, importante observar que o investimento opera como suporte para a geração de emprego (vide o chamado efeito-multiplicador keynesiano), bem como para a ativação econômica ao impedir, quanto mais for encadeada a indústria no âmbito espacial em questão, que qualquer queda da demanda em algum setor ou espaço específico se traduza em imediata crise generalizada da economia. Além disso, observe-se que uma estrutura robusta e encadeada no âmbito do estado contribuiria para a redução de vazamentos de renda via compras, quer para outras unidades federativas, quer via importação, para o exterior, evitando desse modo problemas nas contas externas do próprio País ${ }^{35}$. Mais: o investimento opera (ainda) como antídoto para que pressões de demanda resultem em alta generalizada de preços por conta da capacidade ociosa que caracteriza as empresas de bens de capital, assim como o conjunto da estrutura oligopolista (STEINDL 1996).

Nesse sentido, parece urgente considerar prioritariamente o setor industrial, posto que a sua economia, para crescer sustentadamente, não deve ficar apenas às expensas do setor terciário (que é recorrentemente destacado nas análises sobre o Rio). Para tal, uma

\footnotetext{
${ }^{35}$ Observe-se aqui que $80 \%$ dos fornecedores da Petrobras estão situados fora do ERJ, o que exige adensar 'para dentro' a chamada cadeia produtiva (fluminense) para efeito do seu desenvolvimento.
} 
vez mapeada a estrutura industrial em questão, necessário repensá-la, de sorte que venha ocupar lugar de relevo na agenda do desenvolvimento do ERJ; e, pari passu, fazer com que sejam retomados os investimentos no COMPERJ; lutar para que volte a valer legalmente a política de conteúdo local da exploração do petróleo (que impacta positivamente sobre a indústria naval, por exemplo); idem quanto à retomada dos investimentos federais antes em curso no estado (vide as muitas obras ora paralisadas); estimular a constituição ou o desenvolvimento de algumas cadeias produtivas, tais como a da saúde; etc.

\section{2) O eixo finanças públicas}

O presente eixo é tão fundamental quanto o industrial para a promoção do desenvolvimento do ERJ. Observe-se que o primeiro requer a elaboração de um diagnóstico acerca da matriz industrial a definir (pensado em vista do conjunto dos espaços fluminenses), observados os limites inerentes aos mercados em questão e, é trivial, as forças econômico-políticas envolvidas; já o das finanças requer gerar receitas públicas mexendo com forças sociais poderosíssimas, dada a necessidade de tornar a estrutura tributária progressiva e direcionar os gastos públicos para as maiorias populacionais do estado (que, em termos estritamente econômicos, aponta para o fortalecimento do mercado interno). Mas não haverá outro jeito: ou será isso ou não se terá como fomentar o desenvolvimento sustentado da economia do estado. Acrescente-se que os conflitos a serem estabelecidos exigirão, inclusive e decididamente, envolver o ente federal nessa discussão. Nesses termos, será necessário lutar por uma reforma tributária de caráter progressivo no âmbito federal, dada a sua importância para o desenvolvimento do estado e do conjunto do País ${ }^{36}$.

Mas, para alcançar o intento aqui indicado, será necessário ir além, como segue: questionar a cobrança do ICMS no destino e não na origem, como ocorre com todos os bens e serviços, no caso do petróleo, gás e energia elétrica, itens esses em que o ERJ é 'superavitário'; questionar a atual legislação do REPETRO, posto que ela reduz a receita

\footnotetext{
${ }^{36}$ Pois não é crível que a estrutura regressiva ora existente continue a penalizar o conjunto da nação e dos estados. Exemplo: na França, o Imposto sobre Grandes Fortunas/herança, em tempos nos quais tanto se discute a chamada meritocracia no país, carreia para os cofres públicos, com alíquota bem baixa, cerca de 12 bilhões de Euros/ano. No Brasil, outra ilustração, paga-se tributo sobre a propriedade de veículos automotores, mas não sobre iates e jatinhos etc.
} 
de ICMS do estado quando da importação de equipamentos para extração de petróleo no litoral fluminense; questionar as regras que elevaram os salários e as aposentadorias de membros do poder judiciário do estado, que, sabidamente, extrapolam o teto constitucional estabelecido no País - e que 'sangra' as contas públicas do estado (aliás, de todos os estados brasileiros); questionar as regras de teto dos gastos públicos e sua imbricação direta com a venda de ativos públicos que, ao invés de contribuir para o desenvolvimento do estado, tende a constrangê-lo; etc. Ainda, na busca por recurso para financiar o desenvolvimento do estado, será preciso buscar decididamente agências internacionais, tais como o são o BIRD (Banco Mundial) e o BID (Banco Interamericano de Desenvolvimento).

Isto posto - e apenas assim -, será possível fortalecer agências como a AGERio (Agência Estadual de Fomento) ${ }^{37}$ e a FAPERJ (Fundação de Amparo à Pesquisa do ERJ) - neste último caso, em especial a área de tecnologia, sabidamente fundamental para a promoção do desenvolvimento do ERJ.

\section{3) O eixo dimensão espacial (do desenvolvimento)}

Outra frente propositiva diz respeito à dimensão espacial na medida em que não pode haver desenvolvimento estadual sem que todas as suas regiões sejam devidamente valoradas/incorporadas. Nesses termos, a matriz industrial a ser seguida deve observar, com rigor, na discussão das cadeias produtivas (setoriais e intersetoriais) a serem criadas ou fortalecidas, o papel dos diversos espaços fluminenses - em especial, pelo adensamento populacional e elevada conurbação, o entorno metropolitano do município do Rio de Janeiro, sem perder de vista o necessário combate à megacefalia carioca e à estagnação ou mesmo regressividade em curso em dadas regiões do estado.

Vale lembrar que no período supramencionado da inflexão econômica positiva e do 'milagrinho fluminense' que lhe sucedeu, e mesmo um pouco antes, particularmente

\footnotetext{
37 Trata-se de "uma sociedade de economia mista, vinculada à Secretaria de Estado de Desenvolvimento Econômico e Geração de Emprego e Renda. A Agência tem como objetivo principal estimular o desenvolvimento econômico do estado do Rio de Janeiro, levando como pilares essenciais a responsabilidade socioambiental e as boas práticas de governança. A AGERio investe em projetos de todos os portes, desde a micro à grande empresa, por meio de recursos próprios, repasses de linhas de crédito do Banco Nacional do Desenvolvimento Econômico e Social (BNDES), da Caixa Econômica Federal (CEF)/FGTS e da Financiadora de Estudos e Projetos (FINEP)/INOVACRED. Assim, a empresa contribui para a geração de emprego no estado do Rio de Janeiro e para o aumento da qualidade de vida dos cidadãos" - texto extraído da página da Agência na Internet em 13/06/2019.
} 
no governo Antony Garotinho, em que pese os senões que poderiam ser anotados, houve no ERJ uma série de investimentos de mobilidade urbana na sua capital e de integração rodoviário-espacial entre regiões, tal como: a duplicação de pistas no trecho que liga Macaé a Campos, Niterói a Manilha e Rio a Petrópolis; obras tornando mais adequadas a ligação entre Friburgo e a região dos Lagos; a construção ou recuperação de algumas estradas vicinais; etc. Tudo isso é trivial, rompendo com o relativo isolamento do município-sede em relação ao restante do estado e mesmo entre as regiões interioranas (e vice-versa). Houve, ainda, por conta dos Programas de Aceleração do Crescimento, a construção da já referida alça do Arco Metropolitano ligando a Rio-Petrópolis à rodovia Rio-SP, bem como à Itaguaí; a modernização da Rio-São Paulo (que liga as duas maiores cidades do País). Logo, como escrito em trabalhos anteriores (NATAL, 2005 e 2015), houve ali o ensaio de uma incipiente rede urbana 'puxada' pelos negócios da cadeia de petróleo e gás, pela vontade política aliançada dos governantes de então e pelo aumento de receitas públicas (como já se explicou).

Ou seja: a retomada dos investimentos no estado, uma vez pensada em termos espaciais, contará com uma base nada desprezível... Não se estará começando do zero!

\section{4) O eixo lutas federativas}

Concordando com Sobral (2019), também se defende, neste ensaio, que 'o Rio não é apenas um estudo de caso' (como também não o é a discussão dos demais estados) e que pensar o seu desenvolvimento, tendo essa unidade federativa como ponto de partida, exige pensar o do próprio País. Em suma, seguindo esse autor, entende-se que não há como pensar o desenvolvimento do estado (do Rio e de qualquer outro) sem colocar na arena duas questões nevrálgicas e associadas: a dos contenciosos federativos e a da independência nacional.

Afinal, enquanto esse último aspecto não for enfrentado, todas as unidades federativas continuarão sendo submetidas pelo ente federal aos ditames da banca, que sacrifica as contas públicas em nome do atendimento ao rentismo/especulação financeira; aos ditames dos interesses dos muito ricos (nacionais e estrangeiros), isentos do pagamento dos devidos tributos, o que também sacrifica as contas públicas, posto minimizar a arrecadação para a realização das adequadas e necessárias políticas públicas - sem esquecer das generosas anistias fiscais; aos ditames dos interesses antinacionais e 
antipopulares que insistem na privatização dos ativos públicos, impedindo que empresas como a Petrobras, por exemplo, possam ser elementos de dinamização da economia brasileira (e dos seus diversos espaços) etc. Logo, enquadrados esses interesses minoritários, antinacionais e antipopulares, os referidos contenciosos federativos seriam melhor aclarados, legitimados e colocados em patamar positivo para a discussão do desenvolvimento do País e das suas 'partes'.

Nesses termos, estaria fora de questão isolar o Rio (e qualquer outro estado) e pensá-lo (pensá-los) como estritamente tributário(s) do ente federal. Ou seja, insistindo, as práxis partiriam necessariamente da unidade federativa em tela e situariam seus desafios em termos de políticas públicas para assim entender os desafios e as interações escalares a estabelecer, bem como o seu lugar dentro dessa nova conformação políticosocietária. Daí derivaria que, com esse procedimento, seriam identificados os verdadeiros adversários do desenvolvimento do País e, como anotado, das suas 'partes': os arautos da austeridade fiscal, os que criminalizam os gestores de políticas públicas inovativas que escapam do "mainstream" e os entreguistas que usam a capa do neoliberalismo para ‘apenas' fazer negócios patrimoniais.

5) O eixo produção reflexiva e gestão governamental

Este eixo, face a tudo que aqui se expôs, é uma inevitável consequência; mas, ao mesmo tempo, ponto de partida para que as discussões acerca da economia e do desenvolvimento do ERJ sejam permanentemente embasadas com dados e análises, assim como agente essencial para a criação de espaços verdadeiramente públicos para que elas, as discussões, possam ocorrer de maneira livre e profícua (um adendo: não se tem aqui a pretensão e nem caberia nos limites de um ensaio propor qualquer modelo institucional para que esses desideratos sejam alcançados...).

Já no caso do aspecto gestão governamental, defende-se que é imprescindível tanto avançar na criação de mecanismos de controle e participação verdadeiramente públicos como realizar esforços urgentes para qualificar ininterruptamente a máquina governamental e melhorar as formas da gestão, de sorte que bons diagnósticos e propostas não sejam esterilizados em seus 'escaninhos'. Dado o 'espírito' deste ensaio, ainda, seria de bom tom avançar no sentido da criação de instâncias e instrumentos de planejamento capilarizados (por regiões, por consórcios e formas diversas de associação e cooperação 
entre municípios e escalas regionais etc.), participativos e integrados pelos municípios e com o estabelecimento de acordos com as unidades de ensino e pesquisa espalhadas por todo o estado.

\section{CONSIDERAÇÕES FINAIS}

Este ensaio teve como propósito defender que o ERJ, especialmente sua economia, não está condenado a nenhum atavismo de degradação permanente. Mostrou-se assim que o que ocorreu aproximadamente de meados dos anos 1990 até 2013, em que pese suas limitações, constituiu um emblema das possibilidades existentes de crescimento econômico e dos constrangimentos a enfrentar de maneira a levar essa mesma economia, os espaços e a sociedade como um todo a dias melhores...

Para tal, dadas as teses esgrimidas, em que pese algumas divergências quanto ao diagnóstico, umas mais importantes outras nem tanto, há grande convergência quanto às propostas alinhadas no debate contemporâneo. Em particular, sublinhamos o criativo aporte de Sobral, posto situar questão metodológica de fundo, sem escapismos, conciliações e concessões ao pensamento e às práticas/interesses conservadores. De outra maneira: esses autores, além de propor uma práxis que parta do Rio, aporta à reflexão a necessidade da consideração da escala nacional, mas sem apelo ao Estado Federal Unitário, e sim a um Estado Nacional Federativo para o soerguimento mais coetâneo e conjunto do País (como se indicou ao final da última subseção) - com indicações precisas de diagnóstico, como o é o caso da estrutura industrial fluminense.

Concluindo, cabe ampliar as vozes críticas do Rio e reverberá-las, rompendo assim o bloqueio ideológico existente - aliás, de longa data -; cabe lançar luzes sobre os sujeitos sociais que querem o verdadeiro desenvolvimento econômico, social e civilizatório do ERJ e os que querem apenas jogar jogos patrimonialistas; cabe avançar na pesquisa acerca da matriz industrial a perseguir e no enfrentamento da questão fiscal; etc. Afinal, apenas desse modo será possível ampliar as perspectivas das políticas públicas a serem levadas adiante para o definitivo início sustentado (e sustentável) do desenvolvimento do ERJ (economia, dentro). 


\section{REFERÊNCIAS}

BRANDÃO, C. Território e desenvolvimento - as múltiplas escalas entre o local e o global. Campinas, SP: Unicamp, 2007.

BRUN, A. Desenvolvimento econômico brasileiro. Ijuí/RS: Unijuí; Petrópolis/RJ: Vozes, 2000.

CANO, W. Raízes da concentração industrial em São Paulo. São Paulo: Difel, 1977.

CARDOSO DE MELLO, J. M. O capitalismo tardio. São Paulo: Brasiliense, 1998.

CARDOSO DE MELLO, J. M. Consequências do neoliberalismo. Revista Economia e Sociedade, Campinas/SP: Unicamp, n. 1, ago. 1992.

CARVALHO, L. Diversificação ou especialização: uma análise do processo de mudança estrutural da indústria brasileira nas últimas décadas. Rio de Janeiro: BNDES, 2010.

CARVALHO, L. Valsa brasileira. São Paulo: Todavia, 2018.

CASTRO, A. B.; SOUZA, F. E. P. A economia brasileira em marcha forçada. São Paulo: Paz e Terra, 1985.

COMPANS, R. A emergência do empreendedorismo público na cidade do Rio de Janeiro. 2001. Tese (Doutorado) - Instituto de Pesquisa e Planejamento Urbano e Regional da UFRJ, Rio de Janeiro.

COUTINHO, L. A. A terceira revolução industrial. Revista Economia e Sociedade, Campinas/SP: Unicamp, n. 1, ago. 1992.

CRUZ, J. L. V. da. Projetos nacionais, elites locais e regionalismo. 2003. Tese (Doutorado) - Instituto de Pesquisa e Planejamento Urbano e Regional/UFRJ, Rio de Janeiro, $324 \mathrm{p}$.

FARIA, V. Cinquenta anos de urbanização no Brasil - tendências e perspectivas. Novos Estudos CEBRAP, São Paulo, N. 29, p. 98-119, mar. 1991.

FURTADO, C. Formação econômica do Brasil. São Paulo: Cia. Editora Nacional, 1976.

HARVEY, D. Neoliberalismo - história e implicações. São Paulo: Loyola, 2008.

KALECKI, M. Crescimento e ciclo das economias capitalistas. São Paulo: HUCITEC, 1977.

KEYNES, J. Teoría general de la ocupación, el interés y el dinero. México: Fundo de Cultura Económica, 1971.

KOMATSU, B. Salário mínimo, desigualdade e informalidade. 2013. Dissertação (Mestrado) FEA/USP, São Paulo. (Disponível em “doi:I0.II606/D.I2.2013.tde26032014-I94017”.

LABINI, S. Oligopólio e progresso técnico. São Paulo: Nova Cultural, 1986.

LAGO, L. Desigualdade e segregação na metrópole - o Rio de Janeiro em tempos de crise. Rio de Janeiro: Revan, 2000.

LESSA, C. Autoestima e identidade nacional. Rio de Janeiro: Garamond, 2002. 
LESSA, C. Estratégia de desenvolvimento, 1974-76: sonho e fracasso. 1978. Tese (Doutorado) - IE/UFRJ, Rio de Janeiro.

LESSA, C. O Rio de todos os brasis: uma reflexão em busca da autoestima. São Paulo: Record, 2000.

MARCELINO, I; RABELO, H. Crise fluminense e possíveis caminhos para sua superação. Jornal dos Economistas, N.354, fev. 2019, p. 6-7.

MARICATO, E. O impasse da política urbana no Brasil. Petrópolis, RJ: Vozes, 2011.

MEDEIROS Jr., H. Planejamento ausente, resignação presente: diferenciais negativos do desenvolvimento carioca entre 1991-2000. Coleção Estudos Cariocas. Rio de Janeiro: Instituto Pereira Passos, n. 9, 2009.

MAZZUCATO, M. O Estado Empreendedor: desmascarando o mito do setor público x setor privado. São Paulo: Portfolio-Penguin, 2014.

MELO, H. P. O café e a economia fluminense, 1870-1920. 1993. Rio de Janeiro, Tese (Doutorado) - IE/UFRJ, Rio de Janeiro, 1993, 424 p.

NATAL, J. O estado do Rio de Janeiro pós-1995: dinâmica econômica, rede urbana e questão social. Rio de Janeiro: Publicatti, 2005.

NATAL, J. Cidades e capitalismo - a barbárie urbana contemporânea em diferentes espaços. Rio de Janeiro: Letra Capital, 2015.

NOVAIS, P. Uma estratégia chamada Planejamento Estratégico - deslocamentos espaciais e atribuição de sentidos na teoria do planejamento urbano. Rio de Janeiro: 7 Letras, 2010.

OLIVEIRA, A. De Maxambomba a Nova Iguaçu (1833-1990's): economia e território em processo. 2010. Dissertação (Mestrado) - IPPUR/UFRJ, Rio de Janeiro, 118 p.

OSÓRIO, M.; VERSIANI, M. H. Rio de Janeiro: como sair da crise? Jornal dos Economistas, Rio de Janeiro, N. 354, p. 3-5, fev. 2019.

PEREIRA, P. Dificuldades de implementação da Política Nacional de Desenvolvimento Regional (PNDR): impasses, embates e conflitos. 2009. Dissertação (Mestrado) - IPPUR/UFRJ, Rio de Janeiro, 220pp.

PESSANHA, R. M. A relação transescalar e multidimensional "Petróleo-Porto" como produtora de novas territorialidades. Tese (Doutorado em Políticas Públicas e Formação Humana) - Universidade do Estado do Rio de Janeiro, Rio de Janeiro, RJ, 2017.

POSSAS, M. L. Dinâmica da economia capitalista - uma abordagem teórica. São Paulo: Brasiliense, 1987.

SCHUMPETER, J. Teoria do desenvolvimento econômico. São Paulo: Abril Cultural, 1982. (Coleção Os Economistas).

SILVA, S. Expansão cafeeira e origens da indústria no Brasil. São Paulo: AlfaÔmega, 1976.

SOBRAL, B. O Rio não é apenas um estudo de caso. Jornal dos Economistas, n. 354, fev. 2019, p. 8-9. 
STEINDL, J. Maturidade e estagnação no capitalismo americano. São Paulo: Nova Cultural, 1996.

VAINER, C. Pátria, empresa e mercadoria: notas sobre a estratégia discursiva do Planejamento Estratégico Urbano. In: ARANTES, O.; VAINER, C.; MARICATO, E. A cidade do pensamento único: desmanchando consensos. Petrópolis, RJ: Vozes, 2000, p. 75-103.

VILLAÇA, F. Reflexões sobre as cidades brasileiras. São Paulo: Studio Nobel, 2012.

WACQANT, L. As prisões da miséria. Paris: Raison d'Agir, 1999.

WILKINSON, R.; PICKETT, K. The spirit level: why greater equality makes societies stronger. Nova York: Bloomsbury Press, 2010. 